\title{
Recent Advancements in Spectrophotometric pKa Determinations: A Review
}

\author{
Job Herman Berkhout', Aswatha Ram HN ${ }^{2, *}$ \\ ${ }^{1}$ Faculty of Science, Radboud University, Nijmegen, NETHERLANDS. \\ ${ }^{2}$ Department of Pharmacognosy, Manipal College of Pharmaceutical Sciences, Manipal Academy of Higher Education, Manipal, \\ Karnataka, INDIA.
}

\begin{abstract}
The pKa value is a key feature in Absorption, Distribution, Metabolism and Excretion (ADME) of drugs, thus knowing this value is critical in drug development. In this review, pKa values determined in the past decade, using UV-Vis spectrometry, are discussed. To determine the pKa, four methods were applied; Henderson-Hasselbach, Albert-Serjeant, Bates-Schwarzenbach and Spectrometric titrations. This review will show the value of this aged but well-established technique in the past decade, due to its simplicity, accuracy, cost efficiency and reproducibility.
\end{abstract}

Key words: Albert-Serjeant, Bates-Schwarzenbach, Henderson-Hasselbach, pKa, Spectroscopy, Titrations.

\section{INTRODUCTION}

The acid dissociation constant $(\mathrm{pKa})$ indicates the ionization state of a compound at a given $\mathrm{pH}$. Since Most drug molecules are ionizable, ${ }^{1}$ the ionization state is of uttermost importance in Absorption, Distribution, Metabolism and Excretion (ADME) of drugs. ${ }^{2,3}$ Therefore, the $\mathrm{pKa}$ value of a compound impacts psychochemical properties like: $\mathrm{pH}$ dependent aqueous solubility, protein interaction and membrane permeability. ${ }^{2}$ For this reason compounds with a different $\mathrm{pKa}$ are absorbed in different compartments of the digestive tract, since the different compartments contain a different $\mathrm{pH}$ (e.g. stomach $\mathrm{pH}$ 1-3.5, colon $\mathrm{pH} 5.5-8$, intestine $\mathrm{pH} 5.5-8$ and blood $\mathrm{pH}$ 7.4). ${ }^{4}$ Hence it is crucial to properly understand and analyze the $\mathrm{pKa}$ value of the compound during early drug development.

Although the $\mathrm{pKa}$ is referred to as a constant, it is influenced by the temperature, ionic strength, nd the solvent dielectric constant. ${ }^{5}$ To produce accurate results, these factors need to remain constant thorough the experiments. Since the $\mathrm{pH}$ of a solu- tion is also influenced by these factors, ${ }^{5} \mathrm{pH}$ meters should be calibrated under the same conditions. Temperature $(\mathrm{T})$, ionic strength (IoStr) and solvent heavily impact the pKa value of a compound. Therefore, reports of $\mathrm{pKa}$ values in literature should contain these exact details.

There are many methods suitable for $\mathrm{pKa}$ determination, which have been comprehensively evaluated by Reijenga et al. ${ }^{5}$ Therefore, these methods will not be evaluated here as it is beyond the scope of this review. As novel $\mathrm{pKa}$ values are estimated thorough the years, this article aims to evaluate the spectroscopic determinations of the past decade.

\section{UV-Vis spectrometry}

UV-Vis spectrometry is traditionally one of the most used methods to determine the $\mathrm{pKa}$ of a compound. To this day it is still commonly used due to its availability, accuracy, simplicity and reproducibility. ${ }^{6}$ To use UV-Vis spectrometry for pKa determination, it is required that a chromophore is present close to the ionization site of
Submission Date: 22-02-2019; Revision Date: 17-05-2019; Accepted Date: 14-09-2019

DOI: 10.5530/ijper.53.4s.141 Correspondence: Dr. Aswatha Ram HN, Department of Pharmacognosy, Manipal College of Pharmaceutical Sciences, Manipal Academy of Higher Education, Manipal-576104, Karnataka, INDIA.

Phone: +91-820-2922482 E-mail: aswatharam@gmail. com

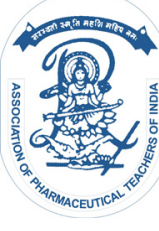

www.ijper.org 
the compound. If this is fulfilled, a distinction in the spectrum of the dissociated and the non-dissociated form of the molecule can be observed. The absorption is then plotted against the $\mathrm{pH}$, from which a sigmoid curve is obtained and the $\mathrm{pKa}$ can be estimated from the inflection point. ${ }^{5}$ Beside curve fitting, there are multiple different approaches with regard to $\mathrm{pKa}$ determination, which will be discussed in this review.

\section{Henderson-Hasselbach method}

The most known pKa determination method is to this day is using the Henderson-Hasselbalch equation (1), established in $1916 .^{7}$

\section{$(1) \mathrm{pH}=\mathrm{pKa}+\log 10\left(\frac{\left[\mathrm{A}^{-}\right]}{[\mathrm{HA}]}\right)$}

It relates $\mathrm{pH}$ and $\mathrm{Pka}$ to the equilibrium concentration of dissociated [A-] and non-dissociated [HA] acids. The pKa value is often experimentally determined by plotting a certain parameter as a function of $\mathrm{pH}$. This results in a sigmoid curve, where the inflection point indicates the pKa. This method was applied by Bartistela et al. to quantify the $\mathrm{pKa}$ values of xanthenes at $30^{\circ} \mathrm{C}$ and the IoStr $[\mathrm{NaCl}] 0.1 \mathrm{M}$. Xanthenes are a class of widly used dyes, which often present three acid-base groups: one carboxylic site and two phenolic sites. ${ }^{8}$ Because of close $\mathrm{pKa}$ values in combination with a strong UV-Vis spectral overlap, multivariate analysis was applied. The determined $\mathrm{pKa}$ values of the dye azafluorescein are: $\mathrm{pKa}_{\mathrm{OH} 1}$ $=2.81, \mathrm{pKa}_{\mathrm{COOH}}=3.88, \mathrm{pKa}_{\mathrm{N}}=5.62$ and $\mathrm{pKa}_{\mathrm{OH} 2}=$ 6.23. For eosin $\mathrm{Y}$ the estimated $\mathrm{pKa}$ values are: $\mathrm{pKa}_{\mathrm{OH}}$ $=2.02$ and $\mathrm{pKa}_{\mathrm{COOH}}=3.8$. To assure the $\mathrm{pKa}$ the attribution, an eosin methyl-ester derivative was synthesized, which contains only the phenol-acid-base group. A pKa of 2.11 was established. This confirms that the $\mathrm{pKa}$ 2.02 of eosin is related to the phenolic center. The $\mathrm{pKa}$ values of rose Bengal $\mathrm{B}$ were estimated to be 1.89 and 3.93, attributed to the carboxylic and $\mathrm{OH}$ group of the xanthene ring respectively. The $\mathrm{pKa}$ values of erythrosine $\mathrm{B}$ were established at 2.35 and 3.79 . These values are attributed to the carboxylic and the phenolic groups respectively. $\mathrm{pKa} \mathrm{OH} 23.79$ was found to be lower than stated by previous studies, potential due to different experimental conditions. The erythrosin methyl ester was synthesized and a pKa of 3.74 was quantified. This corresponds to the phenol group and thus supports that the pKa values of 3.93 for the rose bengal $\mathrm{B}$ and 3.79 for erythrosine B. At last the $\mathrm{pKa}(\mathrm{s})$ of tetranitrofluorescein were determined. Chemometric analysis showed that three $\mathrm{pKa}(\mathrm{s})$ were present in the molecule of which two: $\mathrm{pKa} 0.38$ and $\mathrm{pKa} 2.48$ were concluded, while the lowest $\mathrm{pKa} p \mathrm{H}<0$ was not determined. ${ }^{8}$ FIA/UV-vis, a novel method proven to contain a higher throughput, high sensitivity and has a lower sample consumption, compared to the standard UV-vis methods was developed by Musel et al. FIA/UV-vis was used to establish the $\mathrm{pKa}$ of oxime based acetylcholinesterase reactivators. All pKa values were estimated in a range of 7.008.35 (Figure 1A). ${ }^{9}$ In Hossain et al. UV-spectroscopy was compared to potiometry and RP-HPLC in determination of antimalarial drug lead; Cyclen. Here UVspectroscopy was the most accurate method, since it does not require co-solvents, among others and thus eliminating potential interference. The $\mathrm{pKa}$ value(s) of Cyclen are: 5.9, 6.6 and 8.7. ${ }^{10}$

\section{Albert and Serjeant method}

Another method is to calculate the $\mathrm{pKa}$ of a compound is the Albert-Sergeant method, ${ }^{11}$ which uses the following equations:

(2a)pKa $=\mathrm{pH}+\log 10\left(\frac{\mathrm{AI}-\mathrm{A}}{\mathrm{A}-\mathrm{AM}}\right)(2 \mathrm{~b}) \mathrm{pKa}=\mathrm{pH}+\log 10\left(\frac{\mathrm{AM}-\mathrm{A}}{\mathrm{A}-\mathrm{AI}}\right)$

In this method the compound is considered to be either a weak acid (2a) or a weak base (2b). Here, the $\mathrm{pH}$ is the value recorded on the $\mathrm{pH}$ meter, $\mathrm{D}$ is the absorbance of the compound in the selected buffer, AM and AI indicate the absorbance of the unionized and ionized compound respectively. Using this, a rough estimate of $\mathrm{pKa}$ is required upon which one acidic, one basic and 7 buffer solutions are prepared (with a $\mathrm{pH}$ of the estimated pka value, $\pm 0.2,0.4$ and 0.6$)$. Using this method, the pKa's of Felodipine: 5.07 at IoStr 0.02M. ${ }^{12}$ Resperidone: 8.62, IoStr $0.02 \mathrm{M}^{13}$ and Brimonidine Tartrate: 7.22 , at $25^{\circ} \mathrm{C}$ IoStr $0.3 \mathrm{M}^{14}$ were determined using this equation. This method of $\mathrm{pKa}$ calculation was compared to linear regression in two different studies, which both resulted in a similar $\mathrm{pKa}$ value. In the first study, the $\mathrm{pKa}$ of PPB (1,4-bis(3-(2-pyridyl)pyrazol-1- ylmethyl)benzene) in the solvent mixtures: EtOH $-\mathrm{H}_{2} \mathrm{O}$ and $\mathrm{THF}-\mathrm{H}_{2} \mathrm{O}$, was considerded to be: 10.77 and 11.14 respectively. ${ }^{15}$ In the latter, the $\mathrm{pKa}(\mathrm{s})$ of Nilutamide: approximately 10 and 14 were determined (Figure 1B). ${ }^{16}$ Retention time and electrophoresis mobility are depended on the $\mathrm{pKa}$ of the analyte and the $\mathrm{pH}$ of the mobile phase or analytical medium. Therefore, the pKa of the analyte is determined before HPLC or electrophoresis experiments. ${ }^{17}$ Kuntworbe et al. revisited the $\mathrm{pKa}$ of cryptolepine: 10.99 at $20^{\circ} \mathrm{C}$ and Celebier et al. the pKa of phenazopyridine hydrochloride: 5.17 at $22-23^{\circ} \mathrm{C} .{ }^{18}$ Both studies corrected for the ionic strength.

\section{Bates-Schwarzenbach method}

The Bates-Schwarzenbach method ${ }^{19}$ uses the following equation: 
(3) $\mathrm{pKa}=\mathrm{p}(\mathrm{aH} \gamma \mathrm{CI})-\log 10\left(\frac{\mathrm{DHA}-\mathrm{D}}{\mathrm{D}-\mathrm{DA}^{-}}\right)$

Where $p(\mathrm{aHcCl})$ is an acidity function, $\mathrm{DHA}, \mathrm{DA}^{-}$and $\mathrm{D}$ are the absorbance value in acid, base and buffer, respectively. For this method, there is only one buffer used, where the $\mathrm{pH}$ of the buffer depends on the estimated $\mathrm{pKa}$ of the compound. Domańska et al. and Pobudkowska et al. performed many pKa studies on an array of compounds in different solvents using the Bates-Schwarzenbach method, which is in their opinion the most accurate method. ${ }^{20,21}$ They revisited the compounds: Atropine pKa 10.3, ibuprofen pKa 5.38, promethazine hydrochloride $\mathrm{pKa} 6.47$ and flurbiprofen $\mathrm{pKa} 4.50 .{ }^{21}$ These values were estimated higher compared to previous publications. In another study, the $\mathrm{pKa}$ values of Cimetidine 6.84, Phenylbutazone 5.03,
Fenbufen 4.33, Nitrofurantoin 6.67 and Triamterene 7.16, were revisited (Figure 1C). ${ }^{22}$ The determined $\mathrm{pKa}$ values were similar to the values previously described in literature. Domanska et al. also revisited the $\mathrm{pKa}$ values for the compounds: chlorpromazine hydrochloride: 9.15 , trifluoperazine dihydrochloride: 8.87 , fluphenazine dihydrochloride: 10.01 , thioridazine hydrochloride: 8.89 , promazine hydrochloride: 9.37 and triflupromazine hydrochloride: $9.03 .{ }^{20}$ Here, Fluphenazine dihydrochloride was estimated higher compared to previous studies. Also the $\mathrm{pKa}$ values of Niflumic acid, Flufenamic acid and diclofenac sodium were determined to be $4.42,4.62$ and 5.70 respectively. ${ }^{23}$ Again, each value was considered to be significantly higher compared to previous studies. Pobudkowska and Domańka compared the $\mathrm{pKa}$ values of five compounds at a temperature of 298.1 or 310.2 Kelvin. The results are: flufenamic
A

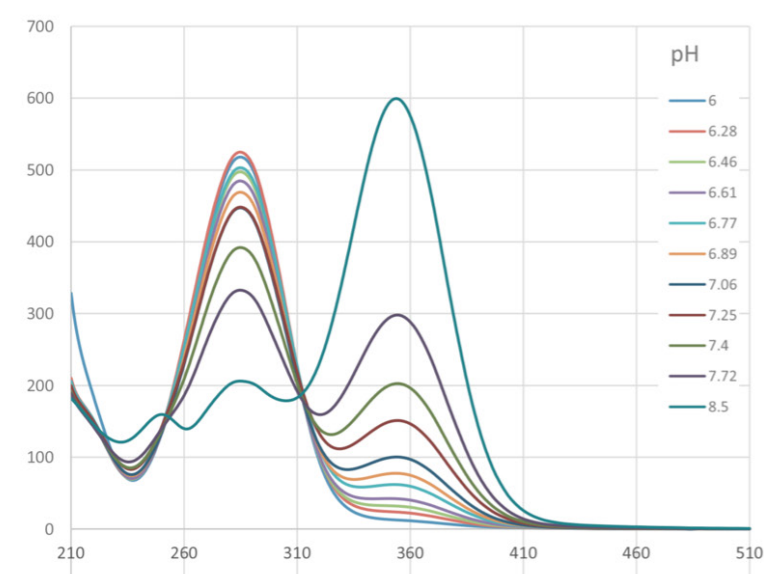

C

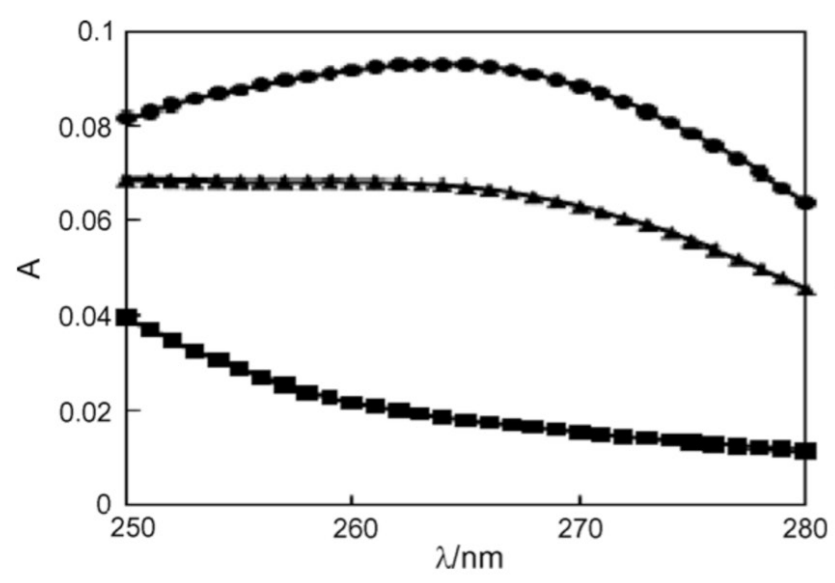

B

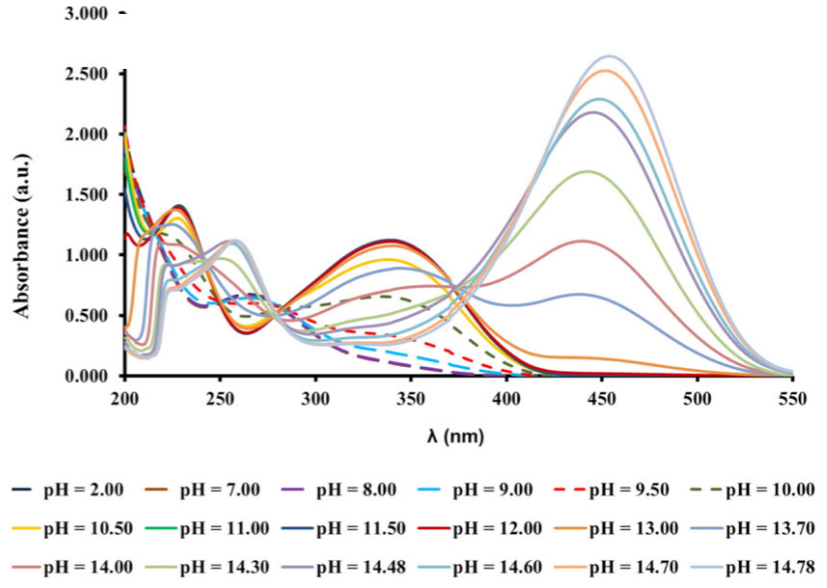

D

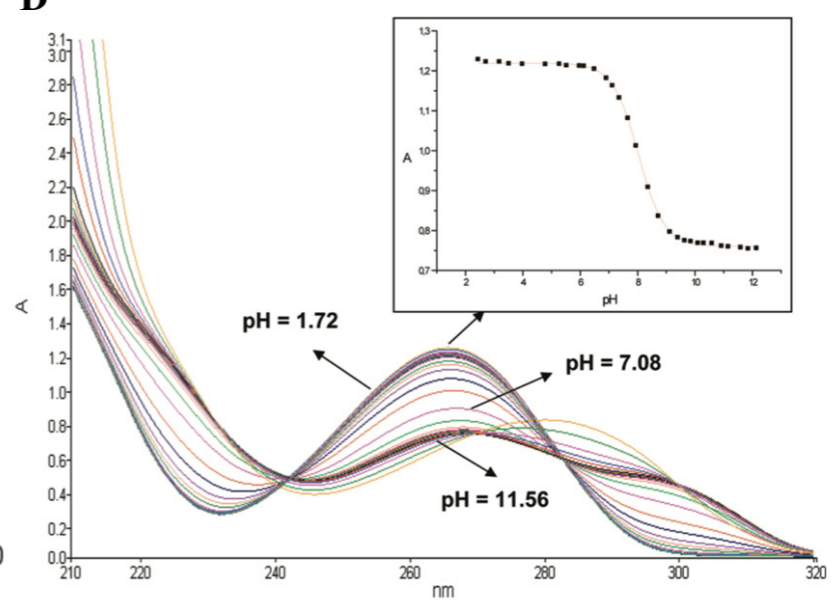

Figure 1: (A) Absorption spectra of Obidoxime, by Musil et al. and pKa value was estimated at 6.67 using the Henderson-Hasselbach method. (B) Absorption spectra of Nilutamide, by Silva et al. and pKa value(s) were estimated at 10 and 14 using AlbertSerjeant method. (C) Absorption spectra of Phenylbutazone, Domanska 2011 et al. $0.1 \mathrm{M} \mathrm{HCl}$, buffer pH 4.7 and $0.1 \mathrm{M} \mathrm{NaOH}$ and pKa value was estimated as $\mathbf{5 . 0 3}$ using Bates-Schwarzenbach method. (D) Absorption spectra of 5-florouracil by acid-base titration curve method at $265 \mathrm{~nm}$ in water by Sanli et al. The pKa was estimated at 8.05 using titrations. 
acid: 4.62 and 5.23, mefenamic acid 3.88 and 4.33, niflumic acid 4.42 and 4.60, diclofenac sodium 5.70 and 4.51 and meclofenamic sodium 4.39 and 3.99 respectively. ${ }^{24}$ Displaying the influence of temperature on the $\mathrm{pKa}$ value. Furthermore, the $\mathrm{pKa}(\mathrm{s})$ of nadolol: 9.30, nimesulide: 7.34 , bifonazole: 5.85 and mefenamic acid: 3.88. ${ }^{25}$ At last, Pobudkowska estimated the pKa of multiple other compounds at a temperature of 298.15 and 310.15. Pka values of Octopamine $\cdot \mathrm{HCl}$, Theophylline, Theobromine, Aminophylline, Lobeline hydrochloride, Perphenazine and Indomethacin and Theobromine at $298.15 \mathrm{~K}$ were determined to be $9.38,9.74,10.35,5.1$, 8.9, 7.3 and 4.5 respectively. At $310.15 \mathrm{~K}$ the $\mathrm{pKa}(\mathrm{s})$ of the compounds: Octopamine $\cdot \mathrm{Hcl}$, Theobromine, aminophylline, Lobeline hydrochloride, Perphenazine and Indomethacin are: 9.85, 8.66, 5.8, 9.0, 7.0 and 3.4 respectively. ${ }^{26-28}$ In the studies without a given temperature or ionic strength; the temperature was $298.5 \mathrm{~K}$ and the ionic strength $0.020 \mathrm{M} .^{19}$

\section{Spectrophotometric titrations}

In $\mathrm{pKa}$ determination by spectrophotometric titrations, the absorption is measured against an increasing $\mathrm{pH}$. Thereafter, (sigmoidal) curve fitting can be applied and the inflection point calculated from the second derivative. Sanli et al. displayed the $\mathrm{pKa}$ values of leucovorin, 5 -fluorouracil and irinotecan as a function of solvent composition at $25^{\circ} \mathrm{C}$ and IoStr $0.1 \mathrm{M}$, since the $\mathrm{pKa}$ differs depending on the mole fraction of acetonitrile present. ${ }^{29}$ It is assumed that water causes preferential solvation of the charged particles. This could then result in a monotonic dependence of the acidity constants of studied compounds on the solvent composition. In water the pKa value(s) of leucovorin are 3.12, 4.60 and 10.0, of 5-fluorouracil 8.05 and of irinotecan 8.71 (Figure 1D). ${ }^{29}$ Vidal-Salgado et al. compared four different methods (two graphical and two mathematical) on $\mathrm{pKa}$ determination of the universal $\mathrm{pH}$ indicator Carlo Ebra 1-11. The combined average $\mathrm{pKa}$ of the four methods was $8.277^{30}$ Ribeiro and Smith examined the pKa of Cefapirin and Ceftiofurusing spectrophotometric titrations and a computational model. ${ }^{31}$ The authors also revised 14 already determined Cephalosporins. The computational models used were Marvin and ACD/ Percepta, which results were compared to experimental obtained data. For ceftiofur, the experimentally determined $\mathrm{pKa}$ was 2.68 , associated to the carboxylic acid group deprotonation. Two values were determined for cefapirin; 2.74, carboxylic acid group deprotonation and 5.13 , associated to pyridinium ring deprotonation. The in silico predicted data argeed with the experimental values, however for cephalosporings having imine and ami- nothiazole groups structurally close, Marin presented problems in pKa prediction. ${ }^{31}$ Ibrutinib contains four ionizable centers, each with a pKa of: $3.22,4.17,6.77$ and 9,82 at $25^{\circ} \mathrm{C}^{32}$ The five thermodynamic dissociation constants from Eltrombag were estimated, depending on ionic strength at a temperature of $25^{\circ} \mathrm{C}$. Which are $2.69,6.97,7.13,7.65$ and $8.30 .{ }^{33} \mathrm{It}$ is suggested that, at acidic $\mathrm{pH}$ melatonin is unstable when interacting with the environment, thus prevoking changes in spectral behavior. Therefore, it is assumed that the currently known $\mathrm{pKa}$ is not valid. Zafra-Roldán et al. managed to correctly estimate the $\mathrm{pKa}$ of melatonin, by protecting it from light and oxygen, which resulted in $\mathrm{pKa}$ values of 5.77 and 10.20. They used spectrometry accompanied by the SQUAD software in their procedure. ${ }^{34}$

\section{CONCLUSION}

The fact that spectroscopy is often used in $\mathrm{pKa}$ determination, proves the value of this aged, but well-preserved technique. The many potential analysis methods allows flexibility of spectroscopy to quantify the $\mathrm{pKa}$ of many different compound types. With the novel computer modeling however, $\mathrm{pKa}$ determination becomes quicker and easier over the years. However, due to limits in computer modeling, still the simplicity, accuracy, low maintenance costs and reproducibility of spectroscopy makes it excel over other methods and thus keeps it uses in future research.

\section{ACKNOWLEDGEMENT}

The authors sincerely thank Manipal College of Pharmaceutical Sciences, Manipal Academy of Higher Education, Manipal, India and Radboud University, the Netherlands for providing necessary facilities to carry out this work.

\section{CONFLICT OF INTEREST}

The authors declare that there is no conflict of interest.

\section{ABBREVIATIONS}

T: Temperature; IoStr: Ionic strength; ADME: Absorption, distribution, metabolism and excretion.

\section{REFERENCES}

1. Wells JI. Pharmaceutical Preformulation: The Physicochemical Properties of Drug Substances. Ellis Horwood Series in Artificial Intelligence Foundations, 1988.

2. Dardonville C. Automated techniques in pKa determination: Low, medium and high-throughput screening methods. Drug Discovery Today: Technologies 2018;27:49-58. 
3. Manallack DT. The pKa Distribution of Drugs: Application to Drug Discovery. Perspectives in Medicinal Chemistry 2007;1:25-38.

4. Sjörgen E, Abrahamsson B, Augustijns P, Becker D, Bolger M, Brewster M, et al. In vivo methods for drug absorption - Comparative physiologies, model selection, correlations with in vitro methods (IVIVC) and applications for formulation/API/excipient characterization including food effects. European Journal of Pharmaceutical Sciences 2014;57(7):99-151.

5. Reijenga J, Hoof van A, Loon van A and Teunissen B. Development of Methods for the Determination of pKa Values. Analytical Chemistry Insights 2013;8:53-71.

6. Babic S, Horvat S, Pavlovic D, Telan-Macan C. Determination of pKa values of active pharmaceutical ingredients. Trends in Analytical Chemistry 2007;26(11):1043-61.

7. Hasselbalch KA. Die Berechnung der Wasserstoffzahl des Blutes aus der freien und gebundenen Kohlensa $\square$ ure desselben, und die Sauerstoffbindung des Blutes als Funktion der Wasserstoffzahl. Biochemische Zeitschrift 1916:112-144.

8. Batistela V, Pellosia D, Souzaa F, Costaa W,Oliveira-Santina S de, Souzaa $\mathrm{V}$, et al. pKa determinations of xanthene derivates in aqueous solutions by multivariate analysis applied to UV-Vis spectrophotometric data. Spectrochimica Acta Part A: Molecular and Biomolecular Spectroscopoy 2011;79(5):889-897.

9. Musil K, Florianova V, Bucek P, Dohnal V, Kuca K, Musilek K. Development and validation of a FIA/UV-vis method for pKa determination of oxime based acetylcholinesterase reactivators. Journal of Pharmaceutical and Biomedical Analysis 2016;117:240-246.

10. Hossain M, Obi C, Shrestha A, Khan M. UV-Metric, pH-Metric and RPHPLC Methods to Evaluate the Multiple pKa Values of a Polyprotic Basic Novel Antimalarial Drug Lead, Cyclen Bisquinoline. Modern chemistry and Applications 2014;2(4):1-7.

11. Albert A and Serjeant E. Ionization constants of Acids and Bases. London: Methuen and Co Ltd, 1962.

12. Pandey M, Jaipal A, Kumar A, Malik R, Charde S. Determination of pKa of felodipine using UV-Visible spectroscopy. Spectrochemica Acta Part A: Molecular and Biomolecular Spectroscopoy 2013:887-90.

13. Dubey S, Singhvi G, Tyagi A, Agarwal H, Krishna K. Spectrophotometric Determination of $\mathrm{pKa}$ and Log $\mathrm{P}$ of Risperidone. Journal of Applied Pharmaceutical Science 2017;7(11):155-8.

14. Bhagav P, Deshpande P, Pandey S, Chandran S. Development and Validation of Stability Indicating UV Spectrophotometric Method for the Estimation of Brimonidine Tartrate in Pure Form, Formulations and Preformulation Studies. Der Pharmacia Lettre 2010;2(3):106-122.

15. Elsherif K, Shuwat H, Najar A. Spectral Study of 1,4-bis(3-(2-pyridyl) pyrazol-1-ylmethyl)benzene (PPB): UV-VIS Absorption Spectra Investigation in Single and Binary Solvents and Spectrophotometric Determination of the Dissociation Constant (pKb). Eurasian Journal of Analytical Chemistry 2017;12(1):67-82.

16. Silva F, Resende S, Araújo A, Prior J. Determination of $\mathrm{pKa}(\mathrm{s})$ of nilutamide through UV-visible spectroscopy". Microchemical Journal 2018;138:303-308.

17. Kuntworbe N, Alany RG, Brimble M, Al-Kassas R. Determination of pKa and forced degradation of the indoloquinoline antimalarial compound cryptolepine hydrochloride. Pharmaceutical Development and Technology 2012;18(4):866-876.

18. Celebier M, Kocak E, Dogan A, Altinöz S, Basci NE. Investigating the physicochemical properties of phenazopyridine hydrochloride using highperformance liquid chromatography and UV-visible spectrophotometry. Marmara Pharmaceuticl Journal. 2019;22(4):528-535.

19. Bates R, Gary R. Journal of Research of the National Bureau of Standards 1965;65:495-505.

20. Domańska U, Pobudkowska A, Pelczarska A. Solubility and pKa determination of six structurally related phenothiazines. International Journal of Pharmaceutics 2011;421(1):135-44.

21. Domańska U, Pobudkowska A, Pelczarska A, Gierycz P. pKa and Solubility of Drugs in Water, Ethanol and 1-Octanol. The Journal of Physical Chemistry B 2009;113(26):8941-7.

22. Domańska U, Pobudkowska A, Pelczarska A, Zukowski L. Modelling, solubility and pKa of five sparingly soluble drugs. Interntional Journal of Pharmaceutics 2010;403(1-2):115-22.

23. Domańska U, Pobudkowska A, Pelczarska A, Zukowski L. Solubility of Sparingly Soluble Drug Derivatives of Anthranilic Acid. Journal of Physical Chemistry B 2011;115(11):2547-54.

24. Pobudkowska A, Domańka U. Study of $\mathrm{pH}$-dependent drugs solubility in water. Chemical Industry and Chemical Engineering 2014;20(1):115-126.

25. Domańska U, Pobudkowska A, Pelczarska A, Gierycz P. Solubility and pKa of select pharmaceuticals in water, ethanol and 1-octanol. The Journal of Chemical Thermodynamics 2010;42(11):1465-72.

26. Pobudkowska A, Szabłowska A, Nosol K. Physicochemical properties and solubilities of drug's hydrochlorides in water and alcohols. International Journal of Pharma Research and Review 2016;5(2):59-72.

27. Pobudkowska A, Domańska U, Kryska J. The physicochemical properties and solubility of pharmaceuticals - methyl xanthines. The Journal of Chemical Thermodynamics 2014;79:41-8.

28. Pobudkowska A, Domańska U, Jurkowska BA, Dymczuk K. Solubility of pharmaceuticals in water and alcohols. Fluid Phase Equilibria 2015;392:5664.

29. Sanli N, Sanli S, Alsancak G. Determination of Dissociation Constants of Folinic Acid (Leucovorin), 5-Fluorouracil and Irinotecan in Hydroorganic Media by a Spectrophotometric Method. J Chem and Eng Data 2010;55(8):2695-2699.

30. Vildal-Salgado L, Vargas-Hernández C. Spectrophotometric Determination of the pKa, Isosbestic Point and Equation of Absorbance vs. pH for a Universal pH Indicator. American Journal of Analytical Chemistry 2014;5:1290-1301.

31. Ribeiro AR, Schmidt TC. Determination of acid dissociation constants (pKa) of cephalosporin antibiotics: Computational and experimental approaches. Chemosphere 2017;169:524-33.

32. A, Corona-Avendaño S, Montes-Sánchez R, Palomar-Pardavé M, RomeroRomo M, Ramírez-Silva M. New insights on the spectrophotometric determination of melatonin pKa values and melatonin- $\beta C D$ inclusion complex formation constant. Spectrochim Acta Part A: Molecular and Biomolecular Spectroscopy 2018;190:442-449.

\section{SUMMARY}

In the drug development, determination of pKa is utmost important in the aspect of ADME. Even though, many techniques and methods are available for its determination, UV-Vis spectrometry has gained its importance in the recent past. Therefore, the various spectrophotometric methods used in the determination of pKa were discussed in this review. Because of the simplicity, accuracy and low maintenance costs, this method is still advantageous in the determination of pKa. 


\section{PICTORIAL ABSTRACT}

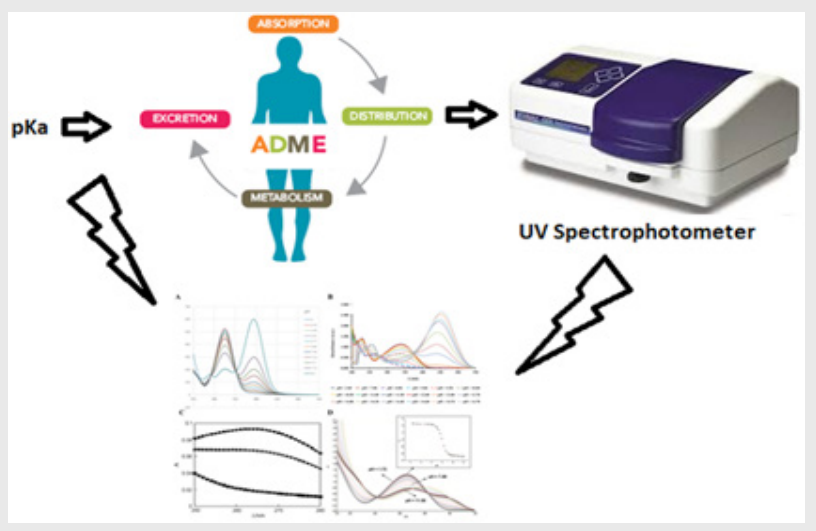

\section{About Authors}

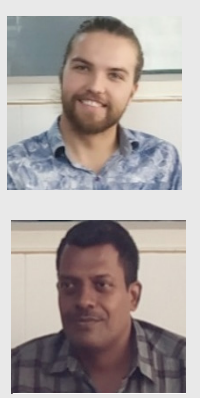

Mr. Job Berkhout, Faculty of Science, Radboud University, Nijmegen, NETHERLANDS.

Dr. Aswatha Ram HN, Department of Pharmacognosy, Manipal College of Pharmaceutical Sciences, Manipal Academy of Higher Education, Manipal, Karnataka, INDIA.

Cite this article: Berkhout $\mathrm{JH}$, Ram AHN. Recent Advancements in Spectrophotometric pKa Determinations: A Review. Indian J of Pharmaceutical Education and Research. 2019;53(4s):s475-s480. 